\title{
Surveillance report: disease trends at New Zealand sexually transmitted disease clinics 1977-1993
}

\author{
P Heather Lyttle
}

\begin{abstract}
Aim-To document trends in sexually transmitted diseases (STDs) recorded by New Zealand STD Clinics from 1977-1993.
\end{abstract}

Methods-Clinic disease figures have been recorded since clinics commenced in the 1920s and were recorded in a comprehensive format from the 1970s. The New Zealand Venereological Society has collated these data since 1986.

Results-The most common STDs in New Zealand clinics are genital warts, non-specific genital infections, chlamydia and genital herpes. Genital Wart infection has been the commonest STD diagnosed in clinics since 1988 and occurred in $17.9 \%$ of new patients in 1993. Non Specific Genital Infections were the commonest diagnosis from 1977 to 1988 affecting $17 \cdot 5 \%$ of new patients in 1993. Chlamydia has shown a fall since the mid 1980 s diagnosed in $5.4 \%$ of new patients in 1993 compared with $14.6 \%$ in 1986. Gonorrhoea incidence has fallen steadily since 1975 affecting only $1 \cdot 1 \%$ new patients in 1993. Genital Herpes numbers tripled from 1977 to 1993 and 54\% are primary cases. HIV Disease has increased clinic workload greatly with screening and counselling conducted in $25 \%$ of new patients in 1993. HIV disease was diagnosed or managed in $0.2 \%$ new clinic patients (49 cases). Syphilis has remained at a low incidence in New Zealand diagnosed in $0.3 \%$ new patients in 1993.

Conclusion-Attendance for the viral diseases, HIV disease, genital warts and genital herpes is increasing while for the bacterial diseases, gonorrhoea and chlamydia is decreasing. The rise in disease numbers since 1990 may be due to meeting service needs rather than a true rise in disease incidence. STD surveillance in New Zealand is improving with new reporting systems being developed.

(Genitourin Med 1994;70:329-335)

New Zealand

Venereological Society-Surveillance Unit

P H Lyttle

Address for correspondence: Dr P H Lyttle, Christchurch Sexual Health Centre Christchurch Hospital, Private Bag 4710,

Christchurch, New Zealand. and KC60 forms. Gonococcal neonatal ophthalmia, congenital syphilis, AIDS and hepatitis B are notifiable diseases in New Zealand. However, generally efforts have been made to follow the British model to avoid notification of sexually transmitted diseases. The New Zealand Venereal Disease Regulations (1982) confer power to Medical Officers of Health and their delegates to initiate contact tracing for five diseases; syphilis, gonorrhoea, chancroid, lymphogranuloma venereum and granuloma inguinale, but do not make these diseases notifiable. Private laboratory isolates of gonorrhoea and syphilis serology were collected from 1976 to 1984 but subsequently discontinued leaving the STD clinic figures as the only national continuous record of STD trends to 1993.

A National Service Development Grant for STD Services was announced in late 1989. From 1990 this led to the upgrading of existing services, additional staffing and equipment and development of additional clinics from 14 in 1989 to 24 clinics by 1993. Only three main centres, Auckland, Wellington and Christchurch, have full-time clinics, while the remainder are open part-time with total doctors hours ranging from 55 to 4 hours per week. The clinics are free to the public, usually based in hospital outpatients or other hospital buildings, with similar clinical screening practices and protocols. Clinic attenders are from a broad cross-section of society, including all socio-economic groups, ethnicity, sexual orientation and sexual practices.

\section{Methods}

During the 1980s the statistical forms were expanded to a unique New Zealand version in order to monitor the increased function and variety of conditions seen at STD clinics, for example abnormal cytology, colposcopy, HIV screening, HIV management, hepatitis B, sexual abuse examinations, dermatological genital conditions. The figures give a mixture of prevalence data in asymptomatic patients, such as females screened for cervical or vaginal infections, and incidence data of symptomatic conditions, such as genital herpes. Details on age, ethnicity and sexual orientation or practices were not collected nationally although some individual clinics have collected these data.

A single patient can have several diagnoses recorded either on their first or subsequent visit to a clinic. A patient is classified as a new patient at the first visit to a clinic or if he or began recording syphilis and gonorrhoea cases from 1920 and non-specific urethritis (NSU) cases from 1968. Clinic new disease diagnosis numbers have been obtained since the early 1970 s in a standardised format based on categories used in the United Kingdom SH 60 


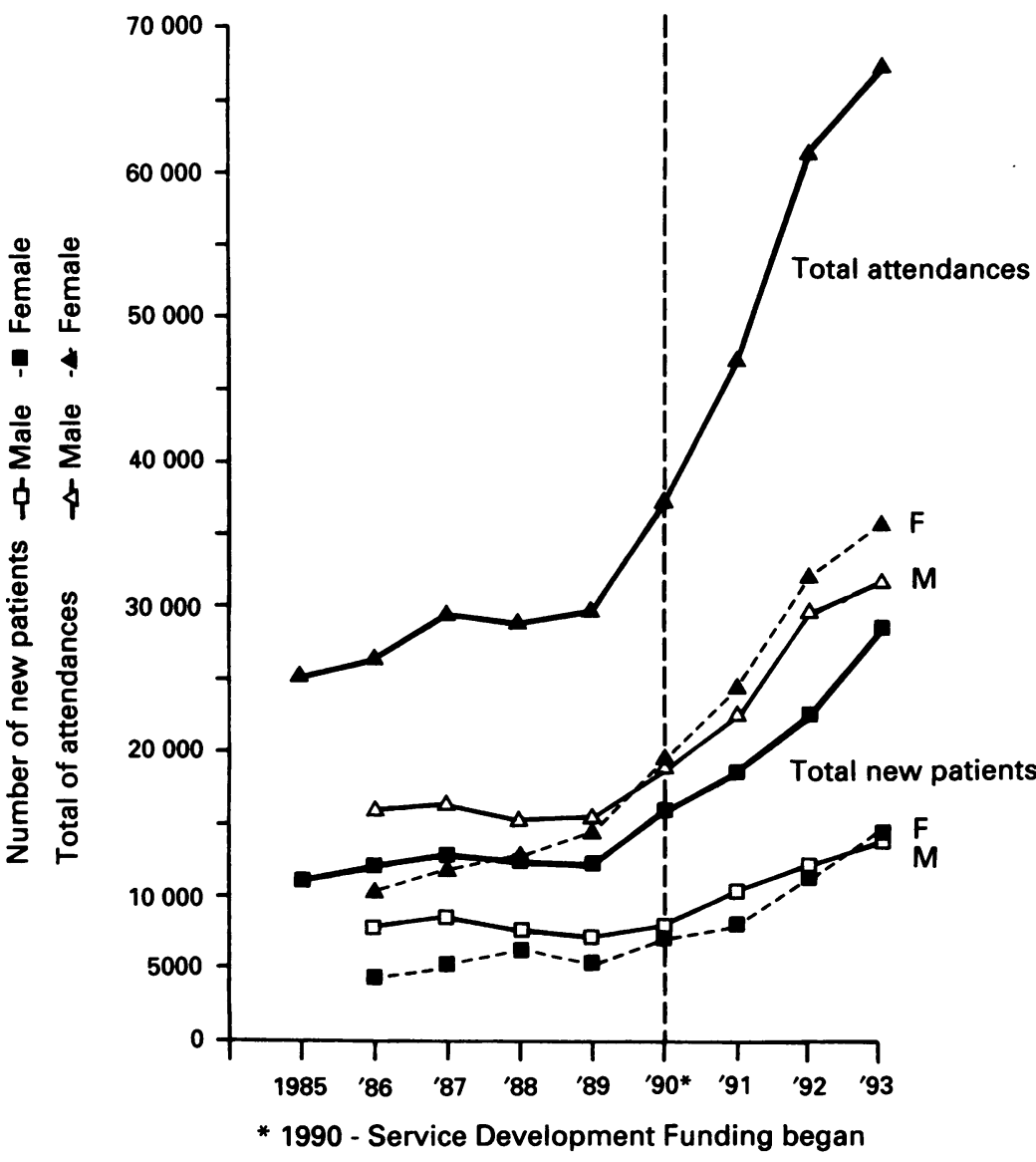

Figure 1 New patients and attendances at New Zealand STD clinics.

she re-attend after a period of three months or more has elapsed since a previous visit. The forms are split into male, female and totals in each category. New patients usually have hepatitis B and syphilis serology taken routinely and human immunodeficiency virus (HIV) testing on request. New females have routine cervical and vaginal swabs and cervical cytology smears, while males have endourethral swabs routinely. Other tests are taken according to symptoms. Most, but not all, new patients have screening and some may have examinations, HIV testing, counselling or pregnancy tests without routine tests. Thus rates of disease from a denominator of new patient numbers must under estimate true incidence diluted by the unknown number who had no screening.

The statistics were forwarded annually to the Department of Health in Wellington. From 1977 to 1986 data on ten sexually transmitted diseases, syphilis, gonorrhoea,
NSU, trichomiasis, scabies, genital warts, candidiasis, genital herpes, pubic lice and molloscum contagiosum were compiled in a table in the "Public Health" the annual report to parliament. ${ }^{1}$ This publication ceased in 1986 and in 1987 representatives of the New Zealand Department of Health asked the NZVS to take over the role of collecting and compiling the clinic data and handed over the 1986 data. Since then clinics annual summaries have been submitted to the author enabling additional information on new patient and attendance numbers and other conditions to be recorded. In 1991 the $\mathrm{NZ}$ Communicable Disease Centre (NZCDC) produced a monthly summary of ten diseases abstracted from the NZVS statistics forms. ${ }^{2}$

In 1992 the NZVS established its own surveillance unit to computerise regional and national disease and workload figures. It was evident by 1992 that there was a need to give clear definitions of disease categories, as confusion was evident in some clinic returns which led to variability and limited the use of these data. In 1994 this surveillance unit is, in conjunction with NZCDC, developing a simplified surveillance form with full definitions, and additional epidemiological data on age and ethnicity for new patients, gonorrhoea, chlamydia and syphilis will be collected.

\section{Results}

From 1985 to 1988 total clinic hours nationally increased from 133 to 175 hours weekly (30\% increase) and the numbers of new patients and attendances both increased by $14 \%$. From 1988 to 1993 , owing to the service development funding, doctors clinic hours increased to 547 hours $(212 \%$ increase), attendances by $132 \%$ and new patient numbers by $118 \%$ (fig 1) (table). In 1993 there were 67321 attendances and 28672 new patients, $49 \cdot 8 \%$ male and $50 \cdot 2 \%$ female. 1993 is the first year in which new female patients have exceeded male patients; in comparison in 1986 the ratio had been $65 \%$ male and $35 \%$ female. The majority of patients are self-referred although in 1993 $6.4 \%$ were referred by a doctor $(1838)$ and an additional $1.7 \%$ (504) from contact tracing. Although the ages of attenders are not recorded nationally, within-clinic surveys indicate the majority $(90 \%)$ of attenders are in the 15-39 year age group (fig 2). The number of new patients in 1993 represents $2 \cdot 1 \%$ of New Zealanders in the 15-39 age group

Cases, new patients and attendances at New Zealand STD clinics 1985-1993

\begin{tabular}{|c|c|c|c|c|c|c|c|c|c|}
\hline & 1985 & 1986 & 1987 & 1988 & 1989 & $1990^{\star}$ & 1991 & 1992 & 1993 \\
\hline \multicolumn{10}{|c|}{ Number of new patients } \\
\hline $\begin{array}{l}\text { Male } \\
\text { Female } \\
\text { Total } \\
\text { Total of attendances }\end{array}$ & $\begin{array}{l}\text { N/A } \\
\text { N/A } \\
11454\end{array}$ & $\begin{array}{r}8013 \\
4328 \\
12341\end{array}$ & $\begin{array}{r}8303 \\
5267 \\
13570\end{array}$ & $\begin{array}{r}7565 \\
5564 \\
13 \quad 129\end{array}$ & $\begin{array}{r}7316 \\
5334 \\
12650\end{array}$ & $\begin{array}{r}8802 \\
7233 \\
16035\end{array}$ & $\begin{array}{r}10303 \\
8595 \\
18898\end{array}$ & $\begin{array}{ll}12 & 610 \\
11 & 804 \\
24 & 414\end{array}$ & $\begin{array}{ll}14 & 286 \\
14 & 386 \\
28 & 672\end{array}$ \\
\hline $\begin{array}{l}\text { Male } \\
\text { Female } \\
\text { Total } \\
\text { Clinic numbers } \\
\text { Doctors hours at clinic }\end{array}$ & $\begin{array}{l}\text { N/A } \\
\text { N/A } \\
25483 \\
\text { s } \quad 12\end{array}$ & $\begin{array}{rr}16 & 179 \\
10 & 275 \\
26 & 454 \\
& 12\end{array}$ & $\begin{array}{rr}16 & 981 \\
12 & 290 \\
29 & 271 \\
& 13\end{array}$ & $\begin{array}{r}15258 \\
13693 \\
28951 \\
13\end{array}$ & $\begin{array}{r}15436 \\
14386 \\
29822 \\
14\end{array}$ & $\begin{array}{rr}18 & 897 \\
19 & 008 \\
37 & 905 \\
& 18\end{array}$ & $\begin{array}{r}23060 \\
24346 \\
47406 \\
\\
23\end{array}$ & $\begin{array}{rr}29 & 709 \\
32 & 109 \\
61 & 818 \\
& 23\end{array}$ & $\begin{array}{rr}31 & 424 \\
35 & 897 \\
67 & 321 \\
& 24\end{array}$ \\
\hline (when surveyed) & 133 & - & - & 175 & - & - & 348 & 502 & 547 \\
\hline
\end{tabular}




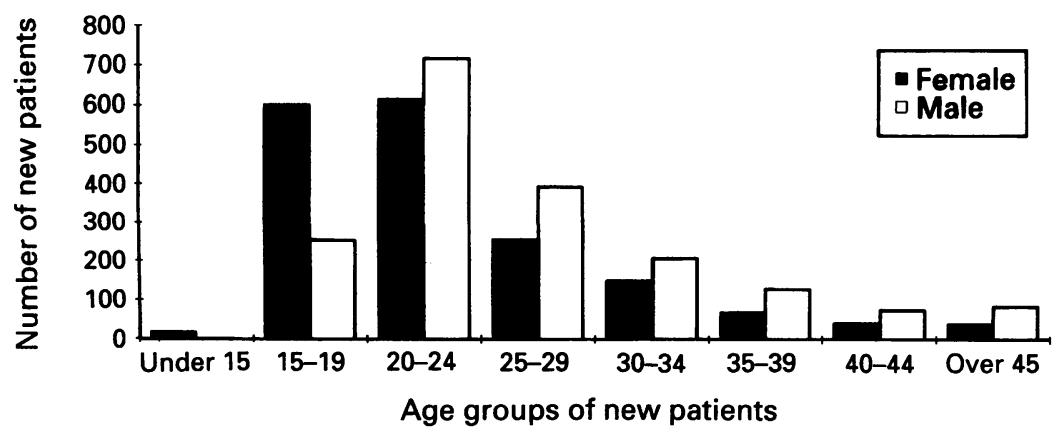

Figure 2 Christchurch Sexual Health Centre Number of New Patients by age groups1993.

(1991 census). Rates of disease in new attenders can only be given from 1986 as this was the first year that new patient numbers were available nationally.

\section{Gonorrhoea}

Gonorrhoea has fallen in New Zealand clinics from a peak of 4267 cases (gathered from seven clinics) in 1975 to 238 cases in 1993 (from 24 clinics) (fig 3). Unfortunately a clinic rate cannot be given for 1975 as the denominator of new patient numbers is not available but Platts gave a national rate of $225 / 100000$ total population in $1976,{ }^{3}$ at a time when private and public laboratory figures were available and noted that clinics saw $45 \%$ of all gonorrhoea diagnoses. Two regions where public and private laboratory figures were available in 1992, Hawkes Bay and Canterbury, gave an incidence of 42 and 32 cases gonorrhoea/100 000 respectively. By contrast the 1992 national rate for Australia, where gonorrhoea is notifiable, was $17 \cdot 4 / 100000 .{ }^{4}$ In $198611 \%$ (1276 cases) of new patients at clinics were treated for gonorrhoea but this fell to only $1 \cdot 1 \%$ treated (328 cases) in 1993.

Male rectal and pharyngeal gonorrhoea infections occurred in $2 \%$ of all cases in 1988 (7 cases) and $2 \cdot 7 \%$ in 1993 ( 4 cases), and in females $6 \%$ in 1988 ( 4 cases) and $5 \cdot 2 \%$ in 1993 (5 cases). Often these sites are screened only if the patient is symptomatic after anal or oral sex, or a known contact, which may not pick up disease in asymptomatic patients. In $19935.5 \%$ of gonorrhoea cases had complications comprising pelvic inflammatory disease
(15 cases), epididymitis/prostatitis (2 cases), Fitz-Hugh Curtis syndrome (15 cases) and disseminated gonococcal infection (1 case).

Gonorrhoea in New Zealand has generally remained sensitive to penicillin. In 1993 clinics recorded only seven cases of penicillinase producing Neiserria gonorrhoeae (PPNG), ie, 3\% of all cases. In 1991 there was a small outbreak of PPNG in Auckland "street kids" which has led to a change in routine treatments in Auckland, from amoxycillin to ciprofloxacin. PPNG cases reported to the NZCDC have risen steadily from five cases in 1976 to 26 cases in 1993 despite the fall in gonorrhoea prevalence; however, it is difficult to evaluate the significance of this as the number of total laboratory gonorrhoea isolates is not known nor the number of tests taken. These cases are usually imported by patients having contact in the higher PPNG prevalence populations of Australia and South East Asia and very little has been "home-grown" owing to vigilant contact tracing. Of the total PPNG cases reported to NZCDC, STD clinics diagnosed $27 \%$ in 1993.

\section{Syphilis}

The syphilis numbers in New Zealand have remained low. A national rate was put at $3 / 100000$ in $1977^{3}$ and according to public and private figures published in $1984^{5}$ at 5/100 000. Australian 1992 data reported a rate of $15 \cdot 4 / 100000^{4}$ of syphilis. Clinic syphilis cases were published in five year groupings from 1920 and in separate years after 1965. Figures fluctuated between 50 and 150 new cases annually peaking in 1989 and 1990 with 164 and 142 cases respectively. In 199382 cases were reported $(0 \cdot 3 \%$ of new patients) compared with 112 cases (1\%) in 1986.

Since the detailed data sheets have been available infectious (first two years of disease) have been differentiated from non-infectious. There has been a steady fall in infectious cases from 47 in 1986 (42\% of total cases) to 17 in 1993 (21\% of total cases) (fig 4). Over the period 1985-1990 the clinics recorded 10 cases of congenital syphilis (under two years) but as it is usually only by chance that STD clinics see these cases it is possible there could be more. From 1991-1993 there were no
Figure 3 Total clinic male and female cases of gonorrhoea NZ STD clinics.

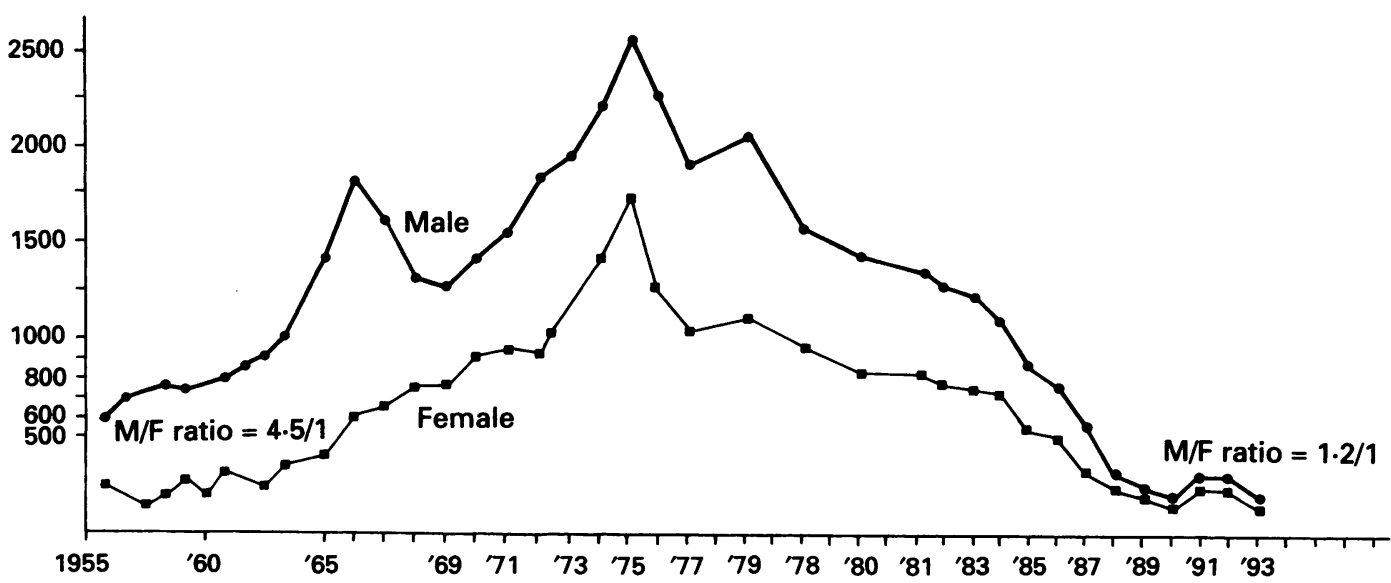




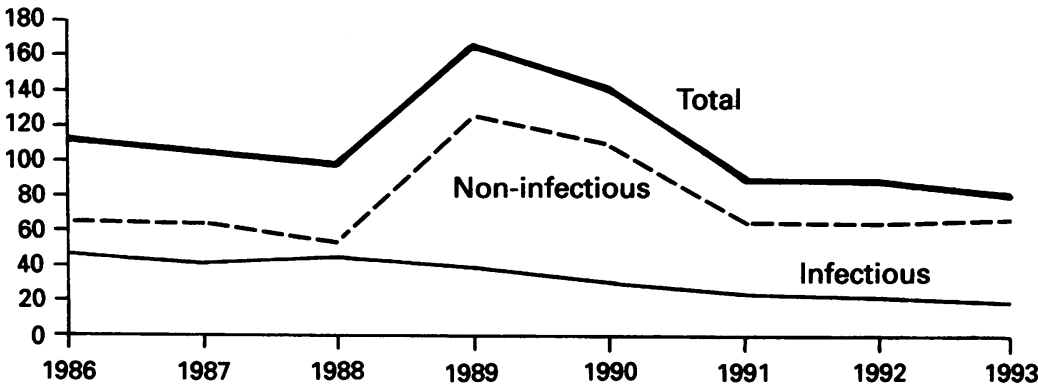

Figure 4 Total number of syphilis cases-infectious and non-infectious at New Zealand STD clinics-1986 onwards.

cases of congenital syphilis under 2 years and only one over 2 years.

Non specific genital infections/chlamydia (fig 5) Non-specific urethritis was recorded from 1974, cervicitis from 1982 and chlamydial infections from 1986. Non-specific genital infection (NSGI) became the commonest diagnosis in New Zealand clinics in 1977 surpassing gonorrhoea but from 1988 it was in turn overtaken by genital warts. If all NSGI treatments and chlamydia cases are included $17 \cdot 5 \%$ of new patients (5032) were treated for NSGI in 1993 compared with $35.3 \%$ (3983) in 1986 . In 1988 when all clinics had chlamydia testing there were 736 cases of chlamydia diagnosed. Chlamydia figures rose to 1697 in 1991 but fell to 1570 cases in 1993 (39\% of NSGI) despite the increased numbers screened.

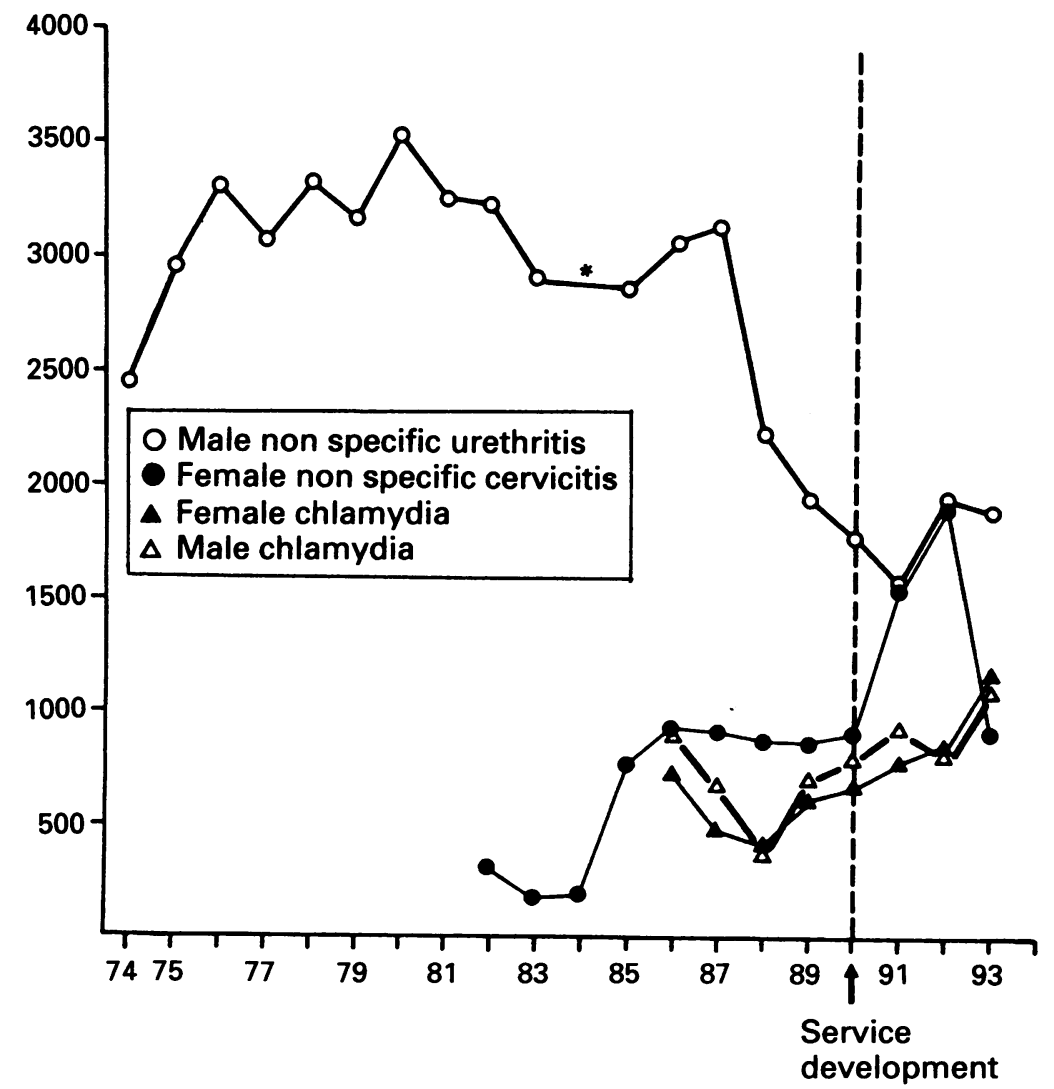

1. * 1984 figures not available

2. Chlamydia recorded from 1986 only

3. Female Cervicitis only recorded from 1982

Figure 5 Non-specific genital infection at NZ STD clinics since 1974 (includes chlamydia and epidemiological treatments).
In 1993 there were 265 cases of pelvic inflammatory disease (PID) due to non-specific genital infections, 104 epididymitis/prostatitis. Chlamydia complications included epididymitis/prostatitis (16 cases) PID (66 cases) Fitz-Hugh Curtis syndrome (6 male and 6 female cases), and adult opthalmia (4 cases). Overall complications occurred in $6 \cdot 2 \%$ chlamydia and $15 \cdot 2 \%$ NSGI cases.

In areas where private and public laboratory figures are available chlamydia figures have fallen since the late 1980s. In the Hawkes Bay region chlamydia rates fell from $552 / 100000$ in 1989 to $360 / 100000$ in 1992 and similarly in Canterbury from $777 / 100000$ in 1987 to $256 / 100000$ in 1992 .

A comparative 1992 national rate in Australia was $56 \cdot 6 / 100000 .^{4}$

\section{Genital warts/abnormal cytology}

Visible condylomata have been recorded in STD clinics since 1977 (577 cases) and became the most common diagnosis after 1989. It was diagnosed in $14.8 \%$ new patients in 1986 ( 1676 cases) and $17.9 \%$ in 1993 (5158 cases) (fig 6). The incidence of warts in new female patients has remained steady at $16.3 \%$ in 1986 (706 cases) and $16 \%$ in 1993 (2311 cases) but increased in males from $12.1 \%$ in 1986 (970 cases) to $19.9 \%$ in 1993 (2847 cases). In $199376 \%$ were a first presentation to an STD Clinic, and $24 \%$ were recurrences who returned more than three months after the last visit. Abnormal cytology defined as dysplasia or cervical intraepithelial neoplasia was diagnosed in $3.9 \%$ of new female patients (568) in 1993, and $4.9 \%$ (719) had colposcopy either performed in clinics (546) or referred elsewhere (173).

\section{Genital herpes}

Genital herpes swabs are usually taken only in symptomatic patients who have suspicious clinical lesions. Since 1977 when herpes recording began there has been a $410 \%$ increase in absolute numbers from 400 to 2044 new cases in 1993. However, the rate of diagnoses has not changed since 1986 when $7.5 \%$ of new patients had herpes (847 cases) to $7 \cdot 1 \%$ in 1993 (fig 6). New Zealand laboratories have also noted an increase in herpes isolations to the point that it is now the most common virus isolated. ${ }^{67}$ Since 1990 diagnoses have been split into primary and secondary herpes. In 1993 54\% (1106 cases) were primary cases, and $46 \%$ (938 cases) were recurrences.

\section{Hepatitis $B$}

There has been increasing awareness that hepatitis B in young people is commonly transmitted by sexual contact and intravenous drug use..$^{8-10}$ In 1990 clinic records on the prevalence of hepatitis B acute infection, carrier states, and past exposure. In 1993 overall $6.9 \%$ of new patients (1984 cases) had antibody to hepatitis B and 1\% (290 cases) were infectious with surface or e.antigen, while 435 "at risk" patients were vaccinated against hepatitis $B$. There is regional variation of 


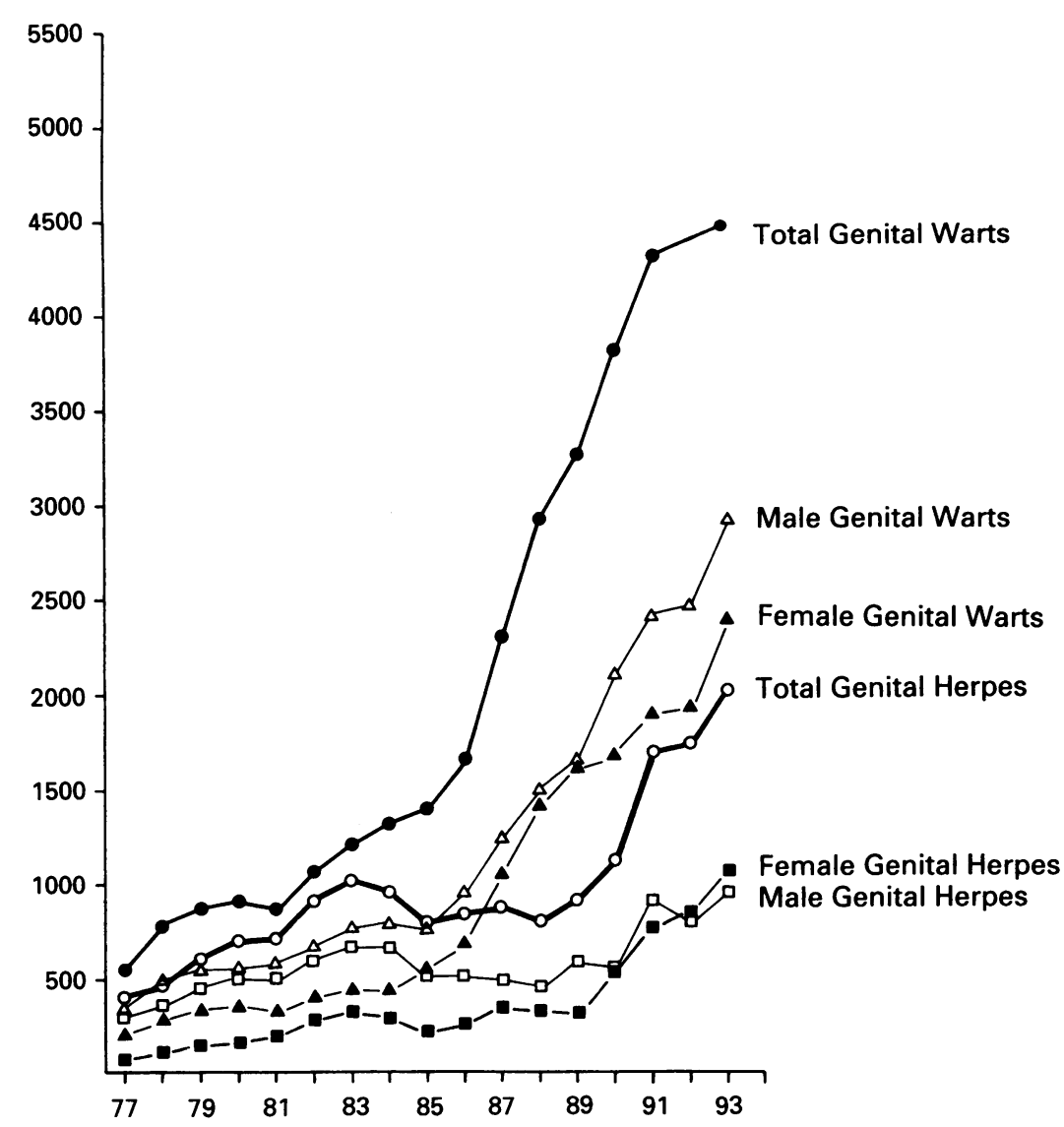

Figure 6 Genital herpes and genital warts in NZ STD clinics.

hepatitis $B$ antibody carriage reflecting the background population incidence from a high of $16.9 \%$ new patients in Whangarei and $16.6 \%$ in Whakatane, to $11.1 \%$ in Auckland and $4.7 \%$ in Wellington. Christchurch, in the South Island, has a low prevalence of hepatitis B compared with other areas; however, the incidence of hepatitis B surface antigen in new clinic patients in 1991 was $1.5 \%$, still 10 times that of the Christchurch blood donor population, ${ }^{11}$ as it had been in a similar study in $1982 .{ }^{12}$ This appears to reflect a difference in mode of transmission in STD clinic attenders from the general population. The influence of ethnicity cannot be commented on as demographic data are not yet available. The current campaign to immunise all New Zealand children against hepatitis $B$ will soon change hepatitis B antibody prevalence in adults which at present largely reflects naturally acquired immunity.

Human immunodeficiency virus (HIV) disease New Zealand has a cumulative notification rate of AIDS similar to the United Kingdom at $12 \cdot 9 / 100000.13$ The risk behaviour of likely modes of transmission of the total 429 AIDS cases to the end of 1993 reported to the AIDS Epidemiology Group, was $83.2 \%$ homosexual/bisexual, $2 \cdot 1 \%$ homosexual/intravenous drug user (IDU), IDU alone $2 \cdot 3 \%$, blood product recipient $1.4 \%$, transfusion related $0.5 \%$, heterosexual $6.5 \%$, perinatal $0.2 \%$ and unknown (all male) 3.7\%. In 199361 of 71 new AIDS cases had sexual transmission as the category of risk behaviour, although full details of where the disease was acquired (in
New Zealand or abroad) was not available. An increase in heterosexual transmission in HIV antibody positive cases was noted in 1993 , with $24.5 \%$ ( 6 males, 16 females) of 90 cases categorised by risk behaviour as heterosexual. ${ }^{13}$

STD clinics began HIV screening in the mid-1980s although figures were not recorded until 1990 (1325 screened). In 19937294 had HIV testing ( $25.4 \%$ of new patients). In all STD clinics, HIV screening is on request and accompanied by counselling, and STD screening is encouraged. In Christchurch a review of HIV screening 1988-1992, has shown that $30 \%$ of those requesting HIV tests have other STDs when screened. ${ }^{14}$ Seventynine cases of positive HIV disease were diagnosed or managed in clinics in 1993. There were 28 (22 male and 6 female) initial diagnoses of HIV disease diagnosed in STD clinics. Of the national total of 90 new diagnoses of HIV-Ab reported in $1993,31 \%$ were first diagnosed in STD clinics (19\% in $1991,21 \%$ in 1992). ${ }^{13}$

Vaginitis, balanitis, scabies and pubic lice In 1993 , candida was diagnosed in $58 \%$, bacterial vaginosis in $38 \%$ and trichomonas in $4 \%$ of all clinic vaginitis cases. Trichomonas vaginalis has fallen steadily from 374 cases in 1977 to 160 in 1993 , ie, $1.1 \%$ of new female patients. Bacterial vaginosis/balanitis figures show an increase from 877 cases in 1987 when first recorded to 1657 cases in 1993 , affecting $11.5 \%$ of new female and $1.1 \%$ of new male patients. Candida figures have trebled since 1977 was diagnosed in $17.4 \%$ of new female patients and $0.5 \%$ new male patients in 1993. Pubic lice figures have fallen from $2.9 \%$ new patients (327) in 1986 to $0.7 \%$ (217) in 1993, while scabies incidence has risen from $0.6 \%$ new patients (67) in 1986 to $2 \%$ (584 cases) in 1993.

\section{Other conditions}

The expanded role as "sexual health" clinics is shown in 1993 with $30.6 \%$ of new patients (8775) screened for health checks without a diagnosis made or treatment required, an increase on 1986 when 2688 (23.8\%) of new patients were screened without a diagnosis. The clinics also conducted STD in-depth counselling in another $9.9 \%$ (2840) of new patients, $8 \cdot 3 \%$ (2396) of new patients had dermatological conditions diagnosed, and $3.9 \%$ (1134) other medical conditions. Contraceptive advice or pregnancy testing also was given to $8 \%$ of new patients (2310) and sexual assault examinations were conducted in $1 \cdot 2 \%$ (343 cases.)

\section{Discussion}

Some New Zealand STD clinics have developed a broader role and been renamed "sexual health clinics" to emphasise this wider service. These new activities include contraceptive advice, sexual assault work, colposcopy, counselling, community education and prevention initiatives such as hepatitis $B$ 
vaccinations. The greatest disease trend affecting clinics has been the seven fold increase in attendance for genital warts in the past 15 years. This had increased clinical workload because of long treatment periods, and follow-up for abnormal cervical cytology, colposcopy and genital biopsies, and an additional time is required for education and counselling of patients and partners. Although the significance of the human papilloma virus (HPV) as a causative agent or co-factor in cervical and genital neoplasia is still debated, the rise of clinical warts, dysplasia and cervical cancer in young women in New Zealand in the late 1980's is of concern. ${ }^{15}$

Falling chlamydia numbers in recent years are possibly due to increased screening by general practitioners. In Christchurch numbers of chlamydia tests at private laboratories have risen seven fold from 1984-1991. One negative effect of this increased awareness of chlamydia is that it can be the only cervical or urethral swab taken, omitting a separate gonococcal swab, to give falsely low gonococcal numbers. The clinics complication rate for chlamydia $(6 \cdot 2 \%)$ and non-specific genital infections $(15 \cdot 2 \%)$ indicate the need to contact these conditions just as assiduously as gonorrhoea.

Similar to other western countries, ${ }^{16-18}$ gonorrhoea has fallen steadily. The $52 \%$ decline in 1976-1982 was considered to be due to rapid case detection and treatment, sensitivity of the organism to antibiotics and contact tracing. However, the next seven years 1982-1989 showed a similar 52\% decline and it is difficult to comment whether public awareness of HIV disease and safer-sex campaigns had affected this decline. Clinic numbers of male pharyngeal and rectal gonorrhoea are very low, but again sampling variability could affect these figures. Overseas reports of increasing rectal gonorrhoea in male patients ${ }^{16}$ indicate this area requires continued surveillance. PPNG has remained at low levels and not warranted a change from penicillin therapy except in Auckland, but the change nationally from IM to oral penicillin in the 1980 s may have changed minimum inhibitory concentration levels.

New Zealanders are great travellers. In the February 1993-January 1994 year 801400 New Zealand residents left for short term trips overseas (about $25 \%$ of the total population). New Zealand tourism is also increasing with 1169000 visitors coming to New Zealand during the same period. ${ }^{19}$ These travellers can import sexually transmitted diseases and we must bear in mind that our near neighbours in the South Pacific, Asia and Australia have a much higher incidence of PPNG, syphilis and heterosexual HIV incidence..$^{20} 21$

Yaws has been endemic in some parts of the Pacific and South East Asia and positive treponemal serology in immigrants from those areas have often been assumed to be yaws. WHO conducted a yaws eradication programme in the south Pacific 1959-1961, so patients born in the south Pacific since then (aged under 35 years) with positive serology should have syphilis considered. The occurrence of congenital syphilis in New Zealand, a developed country with good ante-natal care, serves as a warning to all practitioners to consider positive trepenomal serology as significant.

The majority of New Zealand's HIV disease appears due to sexual transmission ${ }^{17}$ and HIV screening and management has become a significant part of STD clinics workload. STDs and AIDS are inter-linked, as it is suggested that some genital infection can increase the transmission of HIV disease while HIV disease is often found in those who are at risk of STDs or with a past history of STDs. ${ }^{22}{ }^{23} \mathrm{It}$ therefore appears worthwhile to offer STD screening in conjunction with HIV screening.

These data shows changes in disease incidence in STD clinic attendees over the past decade and allows comparisons with data from overseas STD clinics. ${ }^{162425}$ However they have limitations and must be interpreted with caution when looking for national rates. In a publication by $\mathrm{CDNZ}^{2}$ an attempt was made to give regional disease rates from the 1991 STD clinic diagnoses, simply by dividing clinic diagnoses by the total regional population served. However, these figures must underestimate the incidence in the population because they do not include people attending elsewhere or not attending at all including those with asymptomatic infection. The NZVS data indicate that increased new patient and attendance numbers have been generally proportional to increased doctors' clinical hours and improved acceptability and accessability of service, which varies from region to region. Thus disease data will probably reflect service availability until the service fully meets the needs of each region. Recognition of the clinic as a specialist referral centre and local medical under/post graduate teaching are important for medical referrals. Suitable hours open, no cost, availability and gender of doctors, siting and decor of the clinic, reputation of its staff, confidentiality, and quality of service are factors that influence the public to self refer.

The figures have been greatly affected by the service expansion which has led to a doubling in new patients and attendances from 1989-1993 and a change in the ratio of male to female new patients from $35 \%$ female in $1986,42 \%$ in 1989 , to $51 \%$ in 1993 , suggesting increased service accessability and acceptability for female patients. The increased volume screened has led to increased disease absolute numbers. However, these figures do not necessarily reflect increased population incidence but may rather reflect service changes in addressing previously unmet needs. Clinic attendees may have a higher incidence and self-refer because of symptoms, high risk activities, or be in an age group more at risk, but with the recent change to "sexual health" and emphasis on screening in health, lower risk patients have attended.

Surveillance on STDs can be improved markedly and developments are underway by the NZVS Surveillance Unit, namely: gather- 
ing age and ethnic specific data on new patients and certain diseases, development of clear diagnostic definitions, and computerisation of clinic data. Possible future developments could include clinic data on numbers of patients screened, numbers of tests taken, the anonymous reporting of public and private laboratory isolates of chlamydia, gonorrhoea, herpes, trichomonas and positive syphilis serology. Laboratory surveillance could include resistance monitoring and data on the source of organism (New Zealand or overseas). Sentinel general practitioner data on clinical conditions, such as, genital warts, pubic lice and data on sexual orientation or risk behaviour in acquisition of some STDs could also be gathered. Revision of the Venereal Disease Regulations to include chlamydia and other sexually transmissible diseases would also allow wider contact tracing.

\section{Conclusion}

The New Zealand STD service has expanded rapidly as a result of specific funding from 1990, with a doubling of new patient attendance numbers within 3 years and development of a broader sexual health role. The viral diseases: HIV Disease, genital warts and genital herpes are increasing while the bacterial diseases, gonorrhoea and chlamydia are decreasing. However, the changes in disease numbers since 1990 may be due to meeting previously unmet needs rather than a true rise in disease incidence. STD surveillance is improving with new reporting systems being developed.

1 The Public Health. Report of the Department of Health for year ended March 31, 1986. Pursuant to Section 10 of the Health Act 1956.

2 Communicable Disease. New Zealand, May 1992. Vol 92; No 4 41-46.
3 Platts WM. The changing face of sexually transmitted diseases. NZ Med f 1979;90:248-51.

4 Annual report of the National Notifiable Diseases Surveillance System. 1992 Vol 17 No 21 \& No 22 p476-487, 507-508. Communicable Diseases Intelligence (Australia).

5 Department of Health, New Zealand. Sexually Transmitted Diseases. NZ Med ₹ 1985;98:760-1.

$6 \mathrm{Lau} \mathrm{RCH}$, Smith AE, Cursons R, Tobias MI, Shult P, Poole ES. A survey of virus infection in New Zealand Poole ES. A survey of virus infection

7 Lyttle PH. Genital herpes Trends. Letter. NZ Med $\mathcal{f}$ 1988;101:833.

8 Bandaranayake D, Carlson R. Trends in Hepatitis B notifcations, 1976-87. NZ Med F 1990;103:298-301.

9 Flight RJ. Sexually Transmitted Diseases seen in genera practice in Northland: a survey. NZ Med $\mathcal{f} 1982 ; 95$ $217-8$.

10 Stringer HCW, Smith ER, Stewart AC. Hepatitis B in STD Clinics. NZ Med f 1978;87:44-6.

11 McKenna JG, Evans G, Lyttle PH, Couper A. Hepatitis C virus seroprevalence in patients attending a sexual health virus seroprevalence in patients a

12 Faoagali JL. Hepatitis B serology in $1000 \mathrm{VD}$ clinic attenders. NZ. Med $₹ 1981 ; 94: 297-9$.

13 AIDS-New Zealand Issue 20-February 1994 University of Otago, Dunedin. AIDS Epidemiology Unit.

14 Holman R, Lyttle PH, McKenna JG. Concurrent STD screening in patients having HIV testing. Presented NZ Venereological Society Conference 1992 (Unpublished.)

15 Cancer Data. New Registrations and Deaths 1990. National Health Statistics Centre. Wellington Department of Health New Zealand.

16 Catchpole MA. Sexually transmitted diseases in England and Wales, 1981-1990. Communicable Disease Report Review, 2:1, January 1992.

17 Cates W, Hinman AR. Sexually transmitted diseases in the 1990s. N Engl f Med 1991;325:1368.

18 Sexually Transmitted Diseases in South Australia Epidemiologic Report No 6. Public and Environmental Health Division, Adelaide South Australia Health Commission.

19 "Hot off the Press": External migration, January 1994 Wellington Statistics New Zealand

20 Gyaneshaw R, Nsanze H, Singh UP, Pillay S, Seruvatu I. The prevalence of sexually transmitted disease agents in pregnant women in Suva. Aust NZ 7 Obstet Gynaecol 1987;27:213-5.

21 World Health Organisation, Western Pacific Region AIDS Surveillance Report. No 2, January 1994. 197-203.

22 Quinn $T$, Glasser D, Cannon $R$, et al. Role of STDs in HIV transmission. N Engl ₹ Med 1988;318:197-203.

23 Phillips AN. Transmission of HIV. Feedback from the Phillips AN. Transmission of HIV. Feedback from the
Eighth International Conference on AIDS. Amsterdam

24 STDs in England and Wales, 1978-1987. Communicable Disease Report, 1991:1. London

25 Deschryver A, Meheus A. Epidemiology of Sexually Transmitted Diseases-the global picture. Bulletin WHO 1990;65:639. 